\title{
Current logistical capacity is sufficient to deliver the implementation and management of a representative Antarctic protected area system
}

\author{
Kevin A. Hughes \& Susie M. Grant \\ British Antarctic Survey, Natural Environment Research Council, Cambridge, UK
}

\begin{abstract}
Antarctica's terrestrial ecosystems are vulnerable to impacts resulting from climate change and local human activities. The Antarctic Treaty System (ATS) provides for the designation of protected areas through the Protocol on Environmental Protection to the Antarctic Treaty. Unsystematic use of agreed management tools, including Antarctic Specially Protected Areas (ASPAs), has resulted in a protected area system lacking representation across the full range of Antarctic terrestrial ecosystems and Antarctic Conservation Biogeographic Regions (ACBRs). Systematic Conservation Planning (SCP) methods provide established mechanisms to fulfil ATS protected area designation goals. However, how would a continent-wide ASPA system be delivered should appropriate sites be identified using SCP or other methods? Although the rate of area protection has slowed recently, we show that newer Consultative Parties to the Antarctic Treaty are increasingly active as ASPA proponents and may have scope for further engagement with protected area management activities. Furthermore, all 16 ACBRs were found to be within the operational footprint of at least two Parties, indicating that this current logistical footprint could support the implementation and management of a continent-wide ASPA system. Effective management of a representative Antarctic protected areas system could be delivered through greater participation by those Parties with currently more limited protected area management responsibilities and greater use of remote-sensing technologies for protected area monitoring, where appropriate. Crucially, political will to implement an ASPA system identified through SCP approaches may be greater once a pragmatic means of delivery and effective management has been identified.
\end{abstract}

\section{KEYWORDS}

Spatial protection; Environmental Protocol; remote sensing; human impacts; terrestrial biodiversity

\section{ABBREVIATIONS}

ACBR: Antarctic

Conservation Biogeographic Region; ASPA: Antarctic Specially Protected Area; BAS: British Antarctic Survey; CBD: Convention on

Biological Diversity; SCP: Systematic Conservation Planning; SPA: Specially Protected Area; SSSI: Site of Special Scientific Interest

\section{Introduction}

Climate change, pollution from global sources and local impacts are increasingly altering terrestrial Antarctic ecosystems (Bargagli 2008; Tin et al. 2009; Convey 2011). Climate change in the Antarctic Peninsula region has resulted in glacier retreat, iceshelf collapse and changes in water availability and habitat suitability for some terrestrial communities (Turner et al. 2009; Lee et al. 2017). Ice-free areas, in particular, are at risk from tourist and national science operator activities (Hughes et al. 2011; Convey et al. 2012; Bender et al. 2016). Local impacts may include habitat destruction, disturbance of wildlife, pollution and the introduction of non-native species (Tin et al. 2009; Coetzee \& Chown 2016; Hughes, Pertierra et al. 2015; Hughes et al. 2016; Waller et al. 2017).

Antarctic conservation is the responsibility of the 40 Parties that are signatories to the Protocol on Environmental Protection to the Antarctic Treaty (that entered into force in 1998), which includes the 29 Consultative Parties to the Antarctic Treaty (signed in 1959, entered into force in 1961), who govern the region south of latitude $60^{\circ} \mathrm{S}$ (Chown et al. 2012). The first Antarctic protected areas were designated in 1966 and included SPAs that protected natural ecosystems and later SSSIs that protected research sites (Hughes et al. 2013). The SPAs and SSSIs were designated at a time when it was normal practice to establish protected areas close to scientific stations and research areas. The current system of 72 ASPAs was agreed through Annex V to the Protocol on Environmental Protection to the Antarctic Treaty (adopted in 1991, entered into force 2002) and coordinated by the Antarctic Treaty's Committee for Environmental Protection. Under Annex V, existing SPAs and SSSIs were re-designated as ASPAs, and new areas were designated subsequently. Once an ASPA is designated, the provisions of the agreed ASPA Management Plan set out what activities are permitted in the area and how these activities should be undertaken. A permit from an appropriate national authority is required for entry to the ASPA and, in general, recreational visits are prohibited (the main exception being ASPAs that encompass historic huts frequently visited by tourists and national operator personnel) and construction of permanent infrastructure, such as research stations is not permitted. 
In accordance with the Protocol, a review of ASPA management plans must be initiated every five years. Reviews have normally been undertaken by the proponent(s) of the ASPA, although there is nothing in the Protocol to prevent other Parties participating in or take on this role. Parties usually incorporate site visits into this review process to collect new data on the status of the values being protected, and may also undertake more regular monitoring activities.

The Protocol also sets out the goal that protected areas should be designated within a "systematic environmental-geographical framework", taking into consideration the environmental, scientific, intrinsic and other values present in the Treaty area. A study of the spatial distribution of Antarctica's biodiversity records on the continent's ice-free ground identified 16 distinct ACBRs (Fig. 1) (Terauds et al. 2012; Terauds \& Lee 2016). However, it has been suggested that the current distribution of ASPAs does not yet provide representative or integrated protection of Antarctica's regionally distinct biodiversity (Shaw et al. 2014; Tin et al. 2014; Chown et al. 2015; Chown et al. 2017; Coetzee et al. 2017). For example, ASPAs protecting terrestrial and limnetic biodiversity, of which there are 52, are absent from almost a third of the continent's ACBRs (Shaw et al. 2014; Terauds \& Lee 2016). Rather, the distribution of protected areas proposed by individual Parties has largely reflected the location of Parties' research stations, which, in turn, is influenced by factors including national research interests and political considerations (Hughes \& Grant 2017). Consequently, a disproportionately large number of the ASPAs are located in the vicinity of the proponent Party's (or Parties') research stations, and especially in the few regions with established intercontinental links (e.g., ACBR 3 Northwest Antarctic Peninsula and ACBR 9 South Victoria Land) (Hughes et al. 2013; Terauds \& Lee 2016). This distribution may be attributed to the Parties' familiarity with the scientific and environmental values found in the vicinity of existing infrastructure,

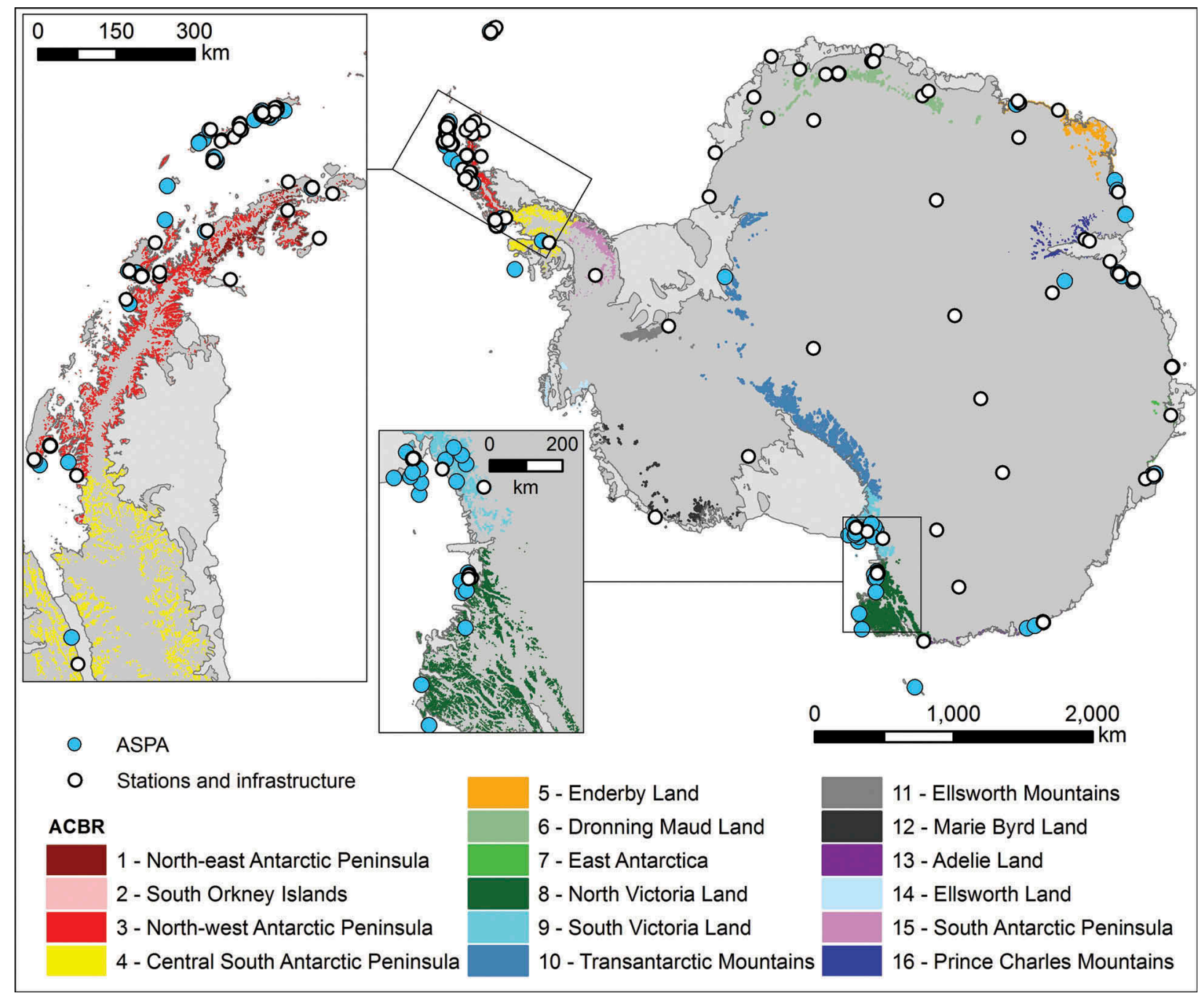

Figure 1. Map of Antarctica showing the ACBRs that encompass the continent's ice-free areas, research stations and facilities run by Antarctic Treaty Consultative Parties' national operators and the current network of ASPAs. 
and the low-resource cost associated with management of areas found locally (Hughes \& Grant 2017).

The CBD Aichi Biodiversity Target 11 calls for at least $17 \%$ of terrestrial and inland water, including areas that are ecologically representative, to be conserved and effectively managed by 2020 (UNEP 2010). Despite the Treaty area not being subject to the CBD, most of the 53 Antarctic Treaty Parties are CBD signatories. While this may indicate a general acceptance of the CBD principles and targets by nations involved in Antarctic affairs, some Parties may consider existing $\mathrm{CBD}$ targets to be less appropriate for Antarctica, given its unique context. Even given this potential perspective, spatial coverage of terrestrial Antarctic protected areas is low, compared with international standards applied outside the Treaty area. Only $1.5 \%$ of Antarctica's ice-free ground is within an ASPA protecting terrestrial biodiversity, compared with a global average of $15.4 \%$ (Juffe-Bignoli et al. 2014; Shaw et al. 2014). Consequently, there may be scope to expand the Antarctic protected areas system, recognizing the standards and targets set in other parts of the world (Chown et al. 2017). The use of an SCP approach (Margules \& Pressey 2000; Pressey \& Bottrill 2009) would enable identification of representative areas for protection across Antarctica, thereby providing the "systematic environmental-geographical framework" advocated by the Protocol (Annex V Article 2) (Coetzee et al. 2017). SCP aims to deliver objective, transparent and effective conservation planning through a staged process including stakeholder involvement, the identification of conservation goals and targets, selecting conservation areas and applying conservation actions therein, and finally maintaining and monitoring established conservation areas (Pressey \& Bottrill 2009).

Protected areas may have little conservation benefit without management and relevant monitoring, as well as adherence to the associated area management plan by all those operating within the area (Hughes \& Grant 2017). The effectiveness of conservation planning or management can be defined through its assessment against agreed objectives or goals. In the case of ASPAs, effective management could be evaluated as the extent to which the existing measures are protecting the defined values, and achieving the aims and objectives set out in the management plan. Effective management must therefore include monitoring and data collection activities that are sufficient to provide the information required for management evaluation as part of review processes.

In their paper setting out the stages required for SCP within Antarctica, Coetzee et al. (2017: 676) identified the major challenge of ensuring "that recommendations of the plan are actually implemented by stakeholders". However, it may be useful to investigate how much logistical capacity exists currently to support the implementation of SCP recommendations, including the designation and management of sites identified for protection across Antarctica. To provide an indication of how much potential there is for greater engagement by Parties in the ASPA system, we investigated each Party's current involvement in the protected area system by recording the number of ASPAs for which they were a proponent. It should be noted that there may be many reasons why some Parties do not propose ASPAs or actively participate in management plan reviews (see discussion section), and a lack of engagement does not indicate necessarily a lack of interest or agreement as to the importance of the protected area system. We also examined the extent of each Party's operational footprint within the 16 ACBRs to identify Parties that may have logistical capacity to manage new ASPAs, once identified by the application of SCP methods (Shaw et al. 2014; Hughes et al. 2016; Coetzee et al. 2017). By "operational footprint" we mean the ACBRs where Parties have year-round or summer-only research facilities or have undertaken substantial research activities in the recent past. Although logistical capacity does not necessarily mean available resources exist to manage protected areas, it may indicate the potential for greater engagement by an individual Party, should it deem this appropriate. Finally, we suggest resourceefficient methods to maximize the effectiveness of existing capacity to facilitate further rapid designation and management of identified sites.

\section{Methods}

Data concerning existing ASPAs were obtained from their management plans, which are available from the Antarctic Treaty Secretariat website (http://www.ats. aq/e/ep_protected.htm) and information on the number of ASPA within each ACBR was amended from Shaw et al. (2014) and Terauds \& Lee (2016). Information on the position and operating status of Antarctic research stations was obtained from the websites of Antarctic national operators or the Council of Managers of National Antarctic Programs (https://www.comnap.aq/Members/ SitePages/Home.aspx).

\section{Results}

\section{Existing ASPA management responsibilities}

Some Parties take on more responsibility for the management of the existing 72 ASPAs than others. 
Table 1. Timeframe over which Consultative Parties became proponents for Antarctic protected areas.

\begin{tabular}{|c|c|c|c|c|c|}
\hline & \multirow[b]{2}{*}{ Party } & \multirow{2}{*}{$\begin{array}{c}\text { Year } \\
\text { consultative } \\
\text { status } \\
\text { recognized by } \\
\text { ATCM } \\
\end{array}$} & \multirow[b]{2}{*}{$\begin{array}{l}\text { Year Party first acts as } \\
\text { proponent for protected } \\
\text { area (SPA, SSSI or ASPA) }\end{array}$} & \multicolumn{2}{|c|}{$\begin{array}{c}\text { Number of new protected areas for which the } \\
\text { Party acts as proponent }\end{array}$} \\
\hline & & & & $\begin{array}{c}\text { Period before Annex V } \\
\text { entered into force } \\
\left(1966-2002^{\mathrm{a}}\right) \\
\end{array}$ & $\begin{array}{l}\text { Period after Annex V } \\
\text { entered into force } \\
(2003-2017) \\
\end{array}$ \\
\hline \multirow{12}{*}{$\begin{array}{l}\text { Parties that were original } \\
\text { signatories to the Antarctic } \\
\text { Treaty }\end{array}$} & US & 1961 & 1966 & 13 & 3 \\
\hline & UK & 1961 & 1966 & 12 & 1 \\
\hline & Australia & 1961 & 1966 & 6 & 6 \\
\hline & New Zealand & 1961 & 1966 & 10 & 1 \\
\hline & Chile & 1961 & 1966 & 8 & - \\
\hline & Argentina & 1961 & 1985 & 3 & $1^{\mathrm{b}}$ \\
\hline & Russian Federation & 1961 & 1975 & 1 & 1 \\
\hline & France & 1961 & 1995 & 1 & 1 \\
\hline & Japan & 1961 & 1987 & 1 & - \\
\hline & Norway & 1961 & 1987 & 1 & - \\
\hline & Belgium & 1961 & - & - & - \\
\hline & South Africa & 1961 & - & - & - \\
\hline \multirow{17}{*}{$\begin{array}{l}\text { Parties for which consultative } \\
\text { status was recognized after the } \\
\text { Treaty entered into force in } \\
1961\end{array}$} & Poland & 1977 & 1979 & 2 & - \\
\hline & Germany & 1981 & - & - & - \\
\hline & Brazil & 1983 & - & - & - \\
\hline & India & 1983 & 2005 & - & 2 \\
\hline & China & 1985 & 2008 & - & 3 \\
\hline & Uruguay & 1985 & - & - & - \\
\hline & Italy & 1987 & 2003 & - & 3 \\
\hline & Spain & 1988 & $2016^{c}$ & - & 1 \\
\hline & Sweden & 1988 & - & - & - \\
\hline & Finland & 1989 & - & - & - \\
\hline & Korea (Republic of) & 1989 & 2009 & - & 1 \\
\hline & Peru & 1989 & - & - & - \\
\hline & Ecuador & 1990 & - & - & - \\
\hline & Netherlands & 1990 & - & - & - \\
\hline & Bulgaria & 1998 & - & - & - \\
\hline & Ukraine & 2004 & - & - & - \\
\hline & Czech Republic & 2014 & - & - & - \\
\hline
\end{tabular}

${ }^{a}$ Annex V to the Protocol on Environmental Protection to the Antarctic Treaty entered into force in 2002. Under Annex V, existing SPAs and SSSIs were re-designated as ASPAs and new areas were designated as ASPAs from this point on. ${ }^{\mathrm{b}}$ In 2015, Argentina joined the UK as a co-proponent of ASPA 140 Mt Flora, Hope Bay, Antarctic Peninsula. ' In 2016 Spain joined the UK and Chile as a co-proponent of ASPA 126 Byers Peninsula, Livingston Island, South Shetland Islands.

Thirteen of the 29 Consultative Parties to the Antarctic Treaty do not act as proponents for any ASPAs and 11 Parties are proponents for four ASPAs or fewer (Table 1). In contrast, five Parties (Australia, Chile, New Zealand, the UK and the US-all of whom are original signatories to the Antarctic Treaty) are proponents or joint proponents for over $80 \%$ of all ASPAs and $75 \%$ of ASPAs protecting terrestrial and limnetic biodiversity. Before Annex V to the Protocol entered into force in 2002, 11 Parties acted as proponents of protected areas, comprising 10 out of the 12 original signatories to the Treaty and one later signatory (Poland). After Annex V entered into force, the number of original signatories proposing new ASPAs fell, while the total number of ATCPs had risen from 12 in 1959 to 27 by 2002 (and stands at 29 in 2018). Only seven Parties proposed ASPAs after 2002 and of those, five acted as proponents or co-managing Parties for only one new ASPA. However, five new Parties became ASPA proponents or co-managing Parties for the first time (Italy, India, China, Korea and Spain), all of whom became Consultative Parties in the 1980s. This demonstrates a gradual shift away from original signatories being the drivers of area protection, and the more active engagement of newer Consultative Parties since Annex $\mathrm{V}$ entered into force.

\section{National operator footprint and protected areas within ACBRs}

The number of Parties whose operational footprint (including infrastructure) extends into each ACBR differs greatly. ACBR 3 Northwest Antarctic Peninsula is within the operational footprint of 18 Parties and contains 43 facilities. In comparison, ACBR 14 Ellsworth Land is within the operational footprint of only two Parties and contain no substantial long-term facilities (Table 2). Nevertheless, the combined operational footprint of all the Parties active in Antarctica encompasses all the ACBRs, and therefore almost all of the continent's ice-free regions and associated biodiversity. For each ACBR, when the number of ASPAs was compared with the number of Parties whose operational footprint extends there, it was clear that some ACBRs occupied by several Parties contain relatively few or no ASPAs (Table 2). For example, ACBR 6 Dronning Maud Land $\left(5523 \mathrm{~km}^{2}\right)$ is within the operational footprint of 
Table 2. Antarctic Treaty Parties with a substantial operational footprint within each ACBR. Party names in boldface indicate the presence of a station or other long-term infrastructure within the ACBR.

\begin{tabular}{|c|c|c|c|c|c|c|c|}
\hline \multirow[b]{2}{*}{$\begin{array}{l}\text { ACBR } \\
\text { no. }\end{array}$} & \multirow[b]{2}{*}{ ACBR name } & \multirow[b]{2}{*}{$\begin{array}{l}\text { ACBR } \\
\text { area } \\
\left(\mathrm{km}^{2}\right)\end{array}$} & \multirow{2}{*}{$\begin{array}{l}\text { Number of ASPAs } \\
\text { (ASPAs protecting } \\
\text { terrestrial } \\
\text { biodiversity) }^{\text {a }}\end{array}$} & \multicolumn{4}{|c|}{ Parties $^{\mathrm{b}}$ whose operational footprint is within the $\mathrm{ACBR}$} \\
\hline & & & & $\begin{array}{c}\text { Parties that are } \\
\text { proponents to }>4 \\
\text { ASPAs }\end{array}$ & $\begin{array}{c}\text { Parties that are } \\
\text { proponents of } 1 \text { to } 4 \\
\text { ASPAs }\end{array}$ & $\begin{array}{l}\text { Parties that are not } \\
\text { proponents to any ASPAs }\end{array}$ & $\begin{array}{c}\text { Total } \\
\text { number of } \\
\text { Parties }\end{array}$ \\
\hline 1 & $\begin{array}{l}\text { Northeast } \\
\text { Antarctic } \\
\text { Peninsula }\end{array}$ & 1215 & $1(0)$ & $\begin{array}{c}3 \\
\mathrm{CHL}, \mathrm{UK}, \mathrm{US}\end{array}$ & $\begin{array}{c}2 \\
\text { ARG, ESP }\end{array}$ & $\begin{array}{c}2 \\
\text { BRA, CZE, URY }\end{array}$ & 7 \\
\hline 2 & $\begin{array}{l}\text { South Orkney } \\
\text { Islands }\end{array}$ & 160 & $3(3)$ & $\begin{array}{c}1 \\
\text { UK }\end{array}$ & $\begin{array}{c}1 \\
\text { ARG }\end{array}$ & - & 2 \\
\hline 3 & $\begin{array}{l}\text { Northwest } \\
\text { Antarctic } \\
\text { Peninsula }\end{array}$ & 5183 & $21(17)$ & $\begin{array}{c}3 \\
\text { CHL, UK, US }\end{array}$ & $\begin{array}{l}6 \\
\text { ARG, CHN, ESP, KOR, } \\
\text { POL, RUS }\end{array}$ & $\begin{array}{c}9 \\
\text { BGR, BRA, CZE, DEU, } \\
\text { ECU, NLD }{ }^{c}, \text { PER, UKR, } \\
\text { URY }\end{array}$ & 18 \\
\hline 4 & $\begin{array}{l}\text { Central South } \\
\text { Antarctic } \\
\text { Peninsula }\end{array}$ & 4962 & 2(2) & $\stackrel{3}{\mathrm{CHL}, \mathrm{UK}}$, US & $\begin{array}{c}1 \\
\text { ARG }\end{array}$ & - & 4 \\
\hline 5 & Enderby Land & 2188 & $1(1)$ & $\begin{array}{c}1 \\
\text { AUS }\end{array}$ & ${ }_{\text {RUS, JPN }}^{2}$ & $\begin{array}{c}1 \\
\text { BLR }\end{array}$ & 4 \\
\hline 6 & $\begin{array}{l}\text { Dronning Maud } \\
\text { Land }\end{array}$ & 5523 & 2(2) & $\begin{array}{l}1 \\
\text { UK }\end{array}$ & $\begin{array}{c}4 \\
\text { IND, } \\
\text { JPN, NOR, RUS }\end{array}$ & $\begin{array}{c}5 \\
\text { BEL, DEU, FIN, SWE, ZAF }\end{array}$ & 10 \\
\hline 7 & East Antarctica & 1109 & 9(8) & $\begin{array}{c}1 \\
\text { AUS }\end{array}$ & $\begin{array}{c}3 \\
\text { CHN, IND, RUS }\end{array}$ & $\begin{array}{c}1 \\
\text { ROU }\end{array}$ & 5 \\
\hline 8 & $\begin{array}{l}\text { North Victoria } \\
\text { Land }\end{array}$ & 9431 & $5(4)^{d}$ & $\begin{array}{c}2 \\
N Z L, \text { US }\end{array}$ & $\begin{array}{c}4 \\
\text { FRA, ITA, KOR, RUS }\end{array}$ & $\begin{array}{c}1 \\
\text { DEU }\end{array}$ & 7 \\
\hline 9 & $\begin{array}{l}\text { South Victoria } \\
\text { Land }\end{array}$ & 10038 & $16(10)^{d}$ & $\begin{array}{c}3 \\
\text { AUS, NZL, US }\end{array}$ & $\begin{array}{c}3 \\
\mathrm{CHN}, \mathrm{ITA}, \mathrm{KOR}\end{array}$ & - & 6 \\
\hline 10 & $\begin{array}{c}\text { Transantarctic } \\
\text { Mountains }\end{array}$ & 18480 & $1(1)$ & NZL, $\stackrel{3}{\mathrm{UK}}, \mathrm{US}$ & $\begin{array}{c}1 \\
\text { ARG }\end{array}$ & - & 4 \\
\hline 11 & $\begin{array}{l}\text { Ellsworth } \\
\text { Mountains }\end{array}$ & 2859 & 0 & ${ }^{2} \mathrm{CHL}, \mathrm{UK}$ & - & - & 2 \\
\hline 12 & Marie Byrd Land & 1128 & 0 & $\begin{array}{l}1 \\
\text { US }\end{array}$ & $\begin{array}{c}1 \\
\text { RUS }\end{array}$ & - & 2 \\
\hline 13 & Adélie Land & 178 & $3(1)$ & - & $\begin{array}{c}2 \\
\text { FRA, ITA }\end{array}$ & - & 2 \\
\hline 14 & Ellsworth Land & 217 & 0 & $\stackrel{2}{\text { UK, US }}$ & - & - & 2 \\
\hline 15 & $\begin{array}{l}\text { South Antarctic } \\
\text { Peninsula }\end{array}$ & 2875 & 0 & ${ }^{2}$ & - & - & 2 \\
\hline 16 & $\begin{array}{l}\text { Prince Charles } \\
\text { Mountains }\end{array}$ & 5992 & $4(3)$ & $\begin{array}{c}1 \\
\text { AUS }\end{array}$ & $\begin{array}{c}2 \\
\text { CHN, RUS }\end{array}$ & - & 3 \\
\hline
\end{tabular}

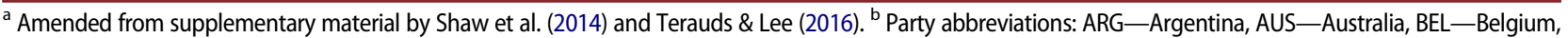
BGR-Bulgaria, BLR-Belarus, BRA-Brazil, CHL-Chile, CHN-China, CZE-Czech Republic, DEU-Germany, ECU-Ecuador, ESP-Spain, FIN-Finland, FRAFrance, IND—India, ITA—Italy, JPN—Japan, KOR—Republic of Korea, NLD—the Netherlands, NOR—Norway, NZL-New Zealand, PER-Peru, POL-Poland, ROU - Romania, RUS-Russian Federation, SWE-Sweden, UK-UK, UKR-Ukraine, URY-Uruguay, US —USA, ZFA-South Africa. ${ }^{\circ}$ Although a Consultative Party to the Antarctic Treaty, the Netherlands does not maintain its own Antarctic research station, but has a facility at the UK's Rothera Research Station. ${ }^{\mathrm{d}}$ Sub-sites of ASPA 175 High Altitude Geothermal Areas of the Ross Sea Region are found within ACBR 8 North Victoria Land and ACBR 9 South Victoria Land.

10 Parties, yet only two ASPAs have been designated, with a combined area of $10.8 \mathrm{~km}^{2}$. Similarly, ACBR 1 Northeast Antarctic Peninsula $\left(1215 \mathrm{~km}^{2}\right)$ is within the operational footprint of six Parties, but contains no ASPAs protecting biodiversity.

\section{Discussion}

Several academic authors have highlighted the unrepresentativeness of the current ASPA system and suggested the need for further protection (Shaw et al. 2014; Hughes, Cowan et al. 2015; Hughes et al. 2016). Despite this, the rate of ASPA designation in the past 10 years has roughly halved compared to earlier periods (Hughes \& Grant 2017), which in large part may be due to the lack of a coherent strategy for Antarctic area protection. Parties are still working towards the co-ordinated delivery of a network of protected areas identified within a systematic environmental-geographical framework, as envisioned during the negotiation of the Protocol, but this goal may be supported through the use of established SCP methods (Coetzee et al. 2017). With the majority of ASPAs having an area of less than $5 \mathrm{~km}^{2}$ (Hughes \& Convey 2010) and only 1.5\% of ice-free ground under special protection (Shaw et al. 2014), the scale of individual areas identified for special protection within each ACBR may need further consideration, with a move towards designation of larger areas likely to help fulfil conservation needs. This is particularly important if the proportion of Antarctic under special protection is to be equivalent to other parts of the world (e.g. Aichi Target 11 of the Strategic Plan for Biodiversity 2011-2020 aims for protection of at least 17\% of terrestrial and inland water areas). 


\section{Drivers of the Antarctic protected area system over time}

In this study, we examined which Parties were proponents of protected areas before and after Annex V to the Protocol entered into force in 2002 and the concept of a "systematic environmental-geographic framework" was established. Up until 2002, SPAs and SSSIs were designated when it was normal practice to establish protected areas close to prioritized research areas and research stations (see Hughes \& Grant 2017). During this time Parties that were original signatories to the Treaty were the main drivers of the protected areas system (Table 1). However, after 2002, all of the Parties that became proponents for ASPAs for the first time had gained consultative status in the 1980s and were not original signatories to the Treaty. Furthermore, the rate of ASPA proposal by some original signatories declined dramatically; for example, the UK, New Zealand and Chile proposed 12, 10 and eight protected areas, respectively, prior to 2002, but proposed only one or none after that date. Of the original signatory Parties, only Australia has increased its rate of proposing protected areas since 2002. Overall, this demonstrates a gradual shift away from original signatories being the drivers of area protection, and the more active engagement of newer Consultative Parties since Annex V entered into force. What could be the reasons for this shift? Until recently the majority of ASPA proposal and management activity has been undertaken by a small number of Parties and original signatories in particular (see Table 1). However, it is unclear how much more capacity these Parties may have for further protected area management, making participation of a wider range of Parties important. The costs of administrative and field activities associated with ASPA designation and management may be minor relative to overall Antarctic logistical costs, but they may still represent a substantial proportion of resources currently allocated by Parties for environmental monitoring, management and protection in accordance with the Protocol (Hughes 2010). During the five-year ASPA management plan review cycle, for each area, managing Parties may need to allocate resources to provide some or all of the following: (i) transportation to the area; (ii) scientific and logistic staff time to support a site visit; (iii) scientific and field equipment; (iv) on-site environmental management (e.g. provision of signage or boundary markers); (v) appropriate scientific expertise for sample or data analysis post-visit; (vi) expertise for drafting or reviewing/revising the ASPA management plan, including the generation of site maps; and (vii) presentation of the revised management plan for consideration by the Committee for Environmental Protection and the Antarctic Treaty Consultative
Meeting. Therefore, given the larger spatial scale of a fully representative protected area system, and that limited resources may be available for on-going management, new and more efficient ASPA management practices may need to be considered, including for example shared logistics, designation of fewer but larger ASPAs, or monitoring using remote-sensing technology (discussed further below). If Antarctica's protected areas are to be effective the development and agreement of a more coordinated ASPA management system will be needed to deliver more consistent monitoring data and better organization and joined-up planning of site visitation by different Parties.

\section{Identifying potential logistical capacity to further develop the protected areas system}

In this study we identify the number of protected areas for which each state acts as the proponent or managing Party. Parties that, up until now, have not acted as proponents to high numbers of protected areas may have the logistical capacity to drive forward the next phase of protected area designation and effective management within a wider Antarctic protected area system, once identified by SCP or other conservation planning approaches. However, we do recognize that the spatially limited logistic capacity of some national operators may reduce opportunities for engagement in this process for some Parties. For the continent as a whole, 11 Consultative Parties were recorded as proponents for four or fewer ASPAs, while a further 13 Consultative Parties were not proponents for any ASPAs (Tables 1, 2). Factors influencing each Party's level of engagement with ASPA designation may include (i) different cultural and ideological perspectives on the benefits of protected areas (Bastmeijer \& Tin 2014; Bastmeijer 2009); (ii) different views on the level of threat to areas not yet covered by the ASPA system, resulting in other aspect of Antarctic management being prioritized; (iii) an absence of locations meriting special protection (as defined by the Protocol) within the operational footprint of some of the Parties; (iv) a lack of awareness or political will to engage with this element of the ATS; or (v) a decision to focus available resources on other scientific or logistical priorities. Nevertheless, capacity may exist within these Parties to take on a greater role in further developing the protected area system as part of an internationally co-ordinated initiative.

Examination of the number of operationally active Parties and ASPAs within each ACBR revealed that the number of Parties active in an ACBR was not always consistent with the number of ASPAs (Table 2). However, for some ACBRs where few ASPAs have been designated to date, the operational presence of several Parties may provide scope for 
further area protection to be established as part of the SCP process. Continent-wide SCP should be an ongoing process of review and management, but once initiated, and potential sites for development of a representative system of ASPAs have been identified and agreed, Parties operating in these ACBRs may be well-placed to manage the sites using existing local logistical capacity, acting either individually or as part of a wider consortium. The most striking opportunities for further protection of biodiversity may be within ACBR 6 Dronning Maud Land, where to date only two ASPAs have been designated for this purpose (equivalent to only $0.2 \%$ of ACBR 6 ), yet 10 Parties are active in the region, and ACBR 1 Northeast Antarctic Peninsula where at least six Parties are active, yet no ASPAs have been designated for protection of biodiversity. Encouragingly, Belgium has indicated an interest in working towards the designation of an ASPA in ACBR 6 (Belgium 2017) and the Czech Republic is leading an international initiative to develop a protected area management plan for sites on James Ross Island (UK \& Czech Republic 2015). Neither of these Parties have acted previously as ASPA proponents, indicating a will by some previously less engaged Parties to become more actively involved in protected area management.

Our study showed that almost half of the ACBRs were within the operational footprint of only three or fewer Parties. However, in recent years the operational footprints of many Parties have continued to expand to support developing scientific requirements (Tin et al. 2009; Tin et al. 2014). This trend is likely to continue and may explain why ASPAs are being designated increasingly at locations that are more distant (> $100 \mathrm{~km}$ ) from the proponent Party's nearest research station (Hughes \& Grant 2017). While an expansion in the footprint of a greater number of Parties may result in increasing human impact it may also facilitate opportunities for greater engagement in management of protected areas across more remote areas of Antarctica (Pertierra et al. 2017).

\section{Developing a pragmatic approach to protected area management}

Expanding the Antarctic protected area system so that it represents the full range of values found across the continent will have implications for resources, but opportunities may exist for cost savings. In accordance with the Protocol, the review of an ASPA management plan must be initiated every five years, and traditionally Parties have incorporated site visits into this process where possible. Some current ASPAs, and candidate areas that may be identified in future planning approaches, are likely to be distant from research stations (up to several hundred kilometres) making site visits for management and monitoring purposes logistically challenging and potentially resource intensive. However, the Protocol does not make site visits a mandatory part of the five-year review process. For ASPAs designated to protect representative habitats in remote areas subject to little human activity, less frequent management visitations may be appropriate (e.g. once every 10-20 years). Rather, review of their status may be achieved using remote-sensing techniques with satellite (Casanovas et al. 2015; Hughes et al. 2016), aircraft (Levy et al. 2014) and/or Remotely Piloted Aircraft System platforms (Chabot \& Bird 2015; Christie et al. 2016; Rümmler et al. 2016), although it is acknowledged that use of these methods will have their own associated costs. Available logistical capacity could then be redirected to designate and manage further and possibly larger representative ASPAs, in accordance with the agreed distribution identified by the planning process. Indeed, some ASPAs may be designated as "inviolate" areas that would, by their nature, require no management site visits at all (Hughes et al. 2011, Hughes, Cowan et al. 2015). Sharing the responsibility for monitoring activities and ASPA reviews would also help to decrease the workload of individual Parties in relation to protected area management. This could be achieved through the designation of more ASPAs with joint or multiple proponents, or by developing collaborative activities with other Parties more active in the area (e.g., Spain recently joined the UK and Chile as a co-managing Party for ASPA 126 Byers Peninsula, Livingston Island) (Hughes \& Grant 2017).

\section{Conclusions}

The recent slowdown in terrestrial Antarctic protected areas designation is a cause for concern (Hughes \& Grant 2017). A strategic and systematic update of the Antarcticprotected areas system is needed in accordance with the principles of the Protocol (Shaw et al. 2014). Several authors have advocated the use of systematic methods, such as SCP, to provide representative area protection across all of Antarctica (Terauds et al. 2012; Shaw et al. 2014; Hughes et al. 2016; Coetzee et al. 2017). Should the recommendations from SCP be agreed by the Antarctic Treaty Consultative Parties, implementation would require coordinated and systematic visitation, protected area designation and ongoing management of identified sites. Crucially, political will to designate and manage candidate sites identified by SCP is likely to be greater if a pragmatic means of delivery has been identified. In response, this study has shown that newer Consultative Parties are becoming increasing engaged in area protection and that current logistical capacity within the Parties is sufficient to deliver a representative Antarcticprotected area system. Using SCP, the Scientific Committee on Antarctic Research is well-placed to 
provide independent advice on suitable areas for protection. Furthermore, the Scientific Committee on Antarctic Research, the Committee for Environmental Protection and the Commission for the Conservation of Antarctic Marine Living Resources may all propose areas for ASPA designation, but have yet to do so. Adoption of a stronger co-ordination role by these organizations, combined with untapped administrative and logistical capacity within the Parties, could greatly enhance the provision of area protection throughout Antarctica. Finally, future protected area planning could harmonize Antarctica Treaty Parties' protected area aspirations with global standards (Shaw et al. 2014; Hughes et al. 2016; Chown et al. 2017).

\section{Acknowledgements}

This paper contributes to the BAS Polar Science for Planet Earth Ecosystems programme, the BAS Environment Office Long Term Monitoring and Survey project and the State of the Antarctic Ecosystem research programme of the Scientific Committee on Antarctic Research. The authors are supported by Natural Environment Research Council core funding to BAS. Laura Gerrish is thanked for map preparation. We also thank two anonymous reviewers for their helpful comments that greatly improved this work.

\section{Disclosure statement}

No potential conflict of interest was reported by the authors.

\section{Funding}

This work was supported by the British Antarctic Survey (core funding).

\section{References}

Bargagli R. 2008. Environmental contamination in Antarctic ecosystems. Science of the Total Environment 400, 212-226.

Bastmeijer K. 2009. Protecting polar wilderness: just a western philosophical idea or a useful concept for regulating human activities in the polar regions? The Yearbook of Polar Law 1, 73-99.

Bastmeijer K. \& Tin T. 2014. Antarctica - a wilderness continent for science: the 'public's dream' as a mission impossible? The Yearbook of Polar Law 6, 559-597.

Belgium 2017. Prior assessment of a proposed Antarctic Specially Protected Area (ASPA) in the Sør Rondane Mountains. Working Paper 42. Antarctic Treaty Consultative Meeting XL, 22 May - 1 June 2017, Beijing.

Bender N.A., Crosbie K. \& Lynch H.J. 2016. Patterns of tourism in the Antarctic Peninsula region: a 20-year analysis. Antarctic Science 28, 194-203.

Casanovas P., Black M., Fretwell P. \& Convey P. 2015. Mapping lichen distribution on the Antarctic Peninsula using remote sensing, lichen spectra and photographic documentation by citizen scientists. Polar Research 34, article no. 25633, doi: 10.3402/polar.v34.25633.
Chabot D. \& Bird D.M. 2015. Wildlife research and management methods in the 21st century: where do unmanned aircraft fit in? Journal of Unmanned Vehicle Systems 3, 137-155.

Chown S.L., Brooks C.M., Terauds A., Le Bohec C., van Klaveren-Impagliazzo C., Whittington J.D. et al. 2017. Antarctica and the strategic plan for biodiversity. PLoS Biology 15, e2001656, doi: 10.1371/journal.pbio.2001656.

Chown S.L., Clarke A., Fraser C.I., Cary S.C., Moon K.L. \& McGeoch M.A. 2015. The changing form of Antarctic biodiversity. Nature 522, 431-438.

Chown S.L., Lee J.E., Hughes K.A., Barnes J., Barrett P.J., Bergstrom D.M., Convey P., Cowan D.A., Crosbie K., Dyer G., Frenot Y., Grant S.M., Herr D., Kennicutt II M. C., Lamers M., Murray A., Possingham H.P., Reid K., Riddle M.J., Ryan P.G., Sanson L., Shaw J.D., Sparrow M.D., Summerhayes C., Terauds A. \& Wall D.H. 2012. Challenges to the future conservation of the Antarctic. Science 337, 158-159.

Christie K.S., Gilbert S.L., Brown C.L., Hatfield M. \& Hanson L. 2016. Unmanned aircraft systems in wildlife research: current and future applications of a transformative technology. Frontiers in Ecology and the Environment 14, 241-251.

Coetzee B.W.T. \& Chown S.L. 2016. A meta-analysis of human disturbance impacts on Antarctic wildlife. Biological Reviews of the Cambridge Philosophical Society 91, 578-596.

Coetzee B.W.T., Convey P. \& Chown S.L. 2017. Expanding the protected area network in Antarctica is urgent and readily achievable. Conservation Letters 10, 670-680.

Convey P. 2011. Antarctic terrestrial biodiversity in a changing world. Polar Biology 34, 1629-1641.

Convey P., Hughes K.A. \& Tina T. 2012. Continental governance and environmental management mechanisms under the Antarctic Treaty System: sufficient for the biodiversity challenges of this century? Biodiversity 13, 1-15.

Hughes K.A. 2010. How committed are we to monitoring human impact in Antarctica? Environmental Research Letters 5, article no. 041001, doi: 10.1088/1748-9326/5/ 4/041001.

Hughes K.A. \& Convey P. 2010. The protection of Antarctic terrestrial ecosystems from inter- and intracontinental transfer of non-indigenous species by human activities: a review of current systems and practices. Global Environmental Change 20, 96-112.

Hughes K.A., Cowan D.A. \& Wilmotte A. 2015. Protection of Antarctic microbial communities - 'out of sight, out of mind'. Frontiers in Microbiology 6, article no. 151, doi: 10.3389/fmicb.2015.00151.

Hughes K.A., Fretwell P., Rae J., Holmes K. \& Fleming A. 2011. Untouched Antarctica: mapping a finite and diminishing environmental resource. Antarctic Science 23, 537-548.

Hughes K.A. \& Grant S.M. 2017. The spatial distribution of Antarctica's protected areas: a product of pragmatism, geopolitics, or conservation need? Environmental Science and Policy 72, 41-51.

Hughes K.A., Ireland L.C., Convey P. \& Fleming A. 2016. Assessing the effectiveness of specially protected areas for conservation of Antarctica's botanical diversity. Conservation Biology 30, 113-120.

Hughes K.A., Pertierra L.R., Molina-Montenegro M. \& Convey P. 2015. Biological invasions in Antarctica: what it the current status and can we respond? Biodiversity and Conservation 24, 1031-1055.

Hughes K.A., Pertierra L.R. \& Walton D.W.H. 2013. Area protection in Antarctica: how can conservation and 
scientific research goals be managed compatibly? Environmental Science and Policy 31, 120-132.

Juffe-Bignoli D., Burgess N.D., Bingham H., Belle E.M.S., de Lima M.G., Deguignet M., Bertzky B., Milam A.N., Martinez-Lopez J., Lewis E., Eassom A., Wicander S., Geldmann J., van Soesbergen A., Arnell A.P., O'Connor B., Park S., Shi Y.N., Danks F.S., MacSharry B. \& Kingston N. 2014. Protected planet report 2014. Cambridge, UK: United Nations Environment Programme.

Lee J.R., Raymond B., Bracegirdle T.J., Chades I., Fuller R.A., Shaw J.D. \& Terauds A. 2017. Climate change drives expansion of Antarctic ice-free habitat. Nature 547, 49-54.

Levy J., Nolin A., Fountain A. \& Head J. 2014. Hyperspectral measurements of wet, dry and saline soils from the McMurdo Dry Valleys: soil moisture properties from remote sensing. Antarctic Science 26, 565-572.

Margules C.R. \& Pressey R.L. 2000. Systematic conservation planning. Nature 405, 243-253.

Pertierra L.R., Hughes K.A., Vega G.C. \& Olalla-Tárraga M.A. 2017. High resolution spatial mapping of human footprint across Antarctica and its implications for the strategic conservation of avifauna. PLoS One 12, e0168280, doi: 10.1371/journal.pone.0168280.

Pressey R.L. \& Bottrill M.C. 2009. Approaches to landscape- and seascape-scale conservation planning: convergence, contrasts and challenges. Oryx 43, 464-475.

Rümmler M.-C., Mustafa O., Maercker J., Peter H.-U. \& Esefeld J. 2016. Measuring the influence of unmanned aerial vehicles on Adélie penguins. Polar Biology 39, 1329-1334.

Shaw J.D., Terauds A., Riddle M.J., Possingham H.P. \& Chown S.L. 2014. Antarctica's protected areas are inadequate, unrepresentative, and at risk. PLoS Biology 12, e1001888, doi: 10.1371/journal.pbio.1001888.

Terauds A., Chown S.L., Morgan F., Peat H.J., Watts D.J., Keys H., Convey P. \& Bergstrom D.M. 2012. Conservation biogeography of the Antarctic. Diversity and Distribution 18, 726-741.
Terauds A. \& Lee J.R. 2016. Antarctic biogeography revisited: updating the Antarctic Conservation Biogeographic Regions. Diversity and Distribution 22, 836-840.

Tin T., Fleming Z., Hughes K.A., Ainley D., Convey P., Moreno C., Pfeiffer S., Scott J. \& Snape I. 2009. Impacts of local human activities on the Antarctic environment: a review. Antarctic Science 21, 3-33.

Tin T., Lamers M., Liggett D., Maher P.T. \& Hughes K.A. 2014. Setting the scene: human activities, environmental impacts and governance arrangements in Antarctica. In T. Tin et al. (eds.): The future of Antarctica: human impacts, strategic planning and values for conservation. Pp. 1-24. Springer: Dordrecht.

Turner J., Bindschadler R., Convey P., Di Prisco G., Fahrbach E., Gutt G., Hodgson D., Mayewski P. \& Summerhayes C. (eds.) 2009. Antarctic climate change and the environment. Cambridge: Scientific Committee on Antarctic Research.

UK \& Czech Republic 2015. Application of the RACER (Rapid Assessment of Circum-Arctic Ecosystem Resilience) Conservation Planning Tool to James Ross Island. Working Paper 38. Antarctic Treaty Consultative Meeting XXXVIII, 1 - 10 June 2015, Sofia.

UNEP 2010. Decision adopted by the Conference of the Parties to the Convention on Biological Diversity at its Tenth Meeting. X/2. The strategic plan for biodiversity 2011-2020 and the Aichi biodiversity targets. United National Environment Programme Convention on Biological Diversity. Accessed on the internet at https:// www.cbd.int/decision/cop/?id=12268 on 15 August 2016.

Waller C.L., Griffiths H.J., Waluda C.M., Thorpe S.E., Alamo I., Moreno B., Pacherres C. \& Hughes K.A. 2017. Microplastics in the Antarctic marine system: an emerging area of research. Science of the Total Environment 598, 220-227. 